\title{
Combinação Peculiar: Estabilidade Econômica, Violência Política e Crime Organizado na Colômbia ${ }^{(1)}$
}

\author{
Peculiar Combination: Economic Stability, \\ Political Violence and Organized Crime in Colombia
}

\author{
Natália Pollachi( \\ Tatiane Fernandes Tavares ${ }^{(*)}$ \\ Carlos Eduardo Carvalho(***)
}

\begin{abstract}
Resumo: A Colômbia apresenta há décadas uma combinação peculiar de estabilidade econômica, atuação prolongada e intensa do crime organizado transnacional e conflito armado interno, inclusive com perda do controle de parcelas do território e da população, elementos típicos de Estados falidos ou fragilizados. Na Colômbia, porém, o Estado mostra elevada capacidade de atuação, apoiado na estabilidade econômica e na capacidade de mobilização e utilização de recursos fiscais. $\mathrm{O}$ artigo destaca três componentes desse quadro: as origens da violência política; os efeitos da "economia da droga"; e a sustentação fiscal da política de "segurança democrática" do governo Uribe. A análise procura contribuir para o entendimento das singularidades do processo colombiano, em especial a preservação das capacidades do Estado.
\end{abstract}

Palavras-chave: Colômbia; Violência Política e Estabilidade Econômica; Economia da Droga; Política de "Segurança Democrática"; Governo Uribe.

\begin{abstract}
Colombia presents peculiar combination of economic stability with activities of transnational organized crime and prolonged armed conflict, including loss of control of portions of territory and population, typical elements of fragile or failed states. In Colombia, however, the State has showed a high capacity for action, based on economic stability; ability to mobilize; and use of fiscal resources. The article highlights three components of this framework: the origins of political violence; the effects of the "drug economy", and the fiscal sustainability of the "democratic security" policy of Uribe government. The analysis seeks to contribute to the understanding of the peculiarities of the Colombian case, the preservation of state capacities in particular.
\end{abstract}

Key words: Colombia; Political violence, and economic stability; Drug economy; "Democratic security" policy; Uribe government.

(1) Versão condensada e revista do relatório final de Iniciação Científica (bolsa PIBIC/CNPq) de Natália Pollachi e do Trabalho de Conclusão de Curso de Tatiane Fernandes Tavares, desenvolvidos no curso de Relações Internacionais da PUC/SP, sob orientação do Professor Carlos Eduardo Carvalho. Agradecemos os comentários e sugestões dos pareceristas anônimos dos Cadernos Prolam/USP e da Comissão de Pesquisa da PUC/SP.

$\left({ }^{*}\right)$ Graduada em Relações Internacionais na Pontifícia Universidade Católica de São Paulo e foi bolsista do PIBIC/CNPq E-mail: $<$ npollachi@hotmail.com>.

(**) Graduada em Relações Internacionais pela Pontifícia Universidade Católica de São Paulo. E-mail: <taty.ft@gmail.com>

(****) Professor do Departamento de Economia e do curso de Relações Internacionais da Pontifícia Universidade Católica de São Paulo.E-mail:<cecarv@uol.com.br>.

Recebido em 13.8.2011 e aceito em 11.10.2011. 


\section{INTRODUÇÃo}

A Colômbia poderia ser considerada um Estado falido ou, ao menos, um Estado fragilizado, em diversos aspectos: perda prolongada de controle sobre partes do território e da população, ação persistente do crime organizado transnacional, violência política continuada, favorecida em parte pelas instituições políticas. Contudo, o país apresenta estabilidade econômica surpreendente, diante da presença desses problemas, e o Estado mantém suas capacidades fiscais, de modo a sustentar programas destinados a equacionar os conflitos e recuperar sua autoridade. Essas capacidades foram essenciais para viabilizar o desenvolvimento da política de "segurança democrática" do governo Álvaro Uribe nos anos recentes, baseada na elevação dos gastos militares a níveis muito elevados sem que isso causasse problemas de natureza fiscal.

Com exceção do Haiti, não há de fato estados falidos na América Latina. Existem vários casos de Estados enfraquecidos em certo número de funções e capacidades, ou de Estados que enfrentam situações temporárias de falência virtual, como ocorreu na Argentina em 2001-2002, no auge da crise econômica do final da conversibilidade, ou no Equador em 1998-2000, com a crise bancária e a forte desconfiança na moeda. Estas situações de colapso virtual tendem a ser curtas e muito intensas, ligadas à ocorrência de crises cambiais e financeiras agudas, mas, em geral, dão lugar ao restabelecimento do quadro anterior ou a uma recuperação econômica acelerada.

O caso da Colômbia se destaca nitidamente pela ausência de crises agudas desse tipo, com exceção do episódio curto de 1999-2000. Esse desempenho singular deve-se muito às exportações de café e de petróleo, em especial na segunda metade dos anos 1970, ao lado de maior solidez fiscal e de indicadores externos favoráveis, dois campos em que a presença de debilidades expressivas contribuiu decisivamente para os casos mais agudos de desestabilização econômica em outros países. Esse bom desempenho no manejo da política econômica amplia os questionamentos a fazer, já que sugere haver certo isolamento entre os problemas da economia e a condução da política econômica, de um lado, e a violência política e a ação do crime organizado, de outro.

Outra hipótese é que a renda do narcotráfico teve efeitos estabilizadores relevantes em diversos momentos, já que a parcela da renda da droga que retorna ao país é muito grande, em relação ao tamanho da economia, e representa uma fonte de divisas expressiva, inclusive em momentos de retração do financiamento externo de curto prazo, sujeito às flutuações de expectativas nos países centrais. Há evidências de que o estado colombiano estimulou a internalização desses recursos em diversos momentos, por meio de operações de "branqueamento" facilitadas por medidas como anistias tributárias, destinadas a estimular investimentos e a equilibrar as contas externas do país. Essa seria uma explicação para o fato de a Colômbia ter sido o único país latino-americano, dentre os de porte médio e grande, a não ter sofrido recessão e restrições cambiais agudas na crise dos anos 1980 .

A relação próxima com os Estados Unidos é outro elemento a considerar. A Colômbia se destaca pela singularidade de ter sofrido acusações fortes de conivência com o narcotráfico em níveis elevados do Estado e de ter mantido negociação com grupos considerados terroristas em nível internacional, e ainda assim não ter sido afastada da convivência internacional, 
ao contrário dos Estados considerados "párias". Esta posição externa foi muito favorecida pelo tradicional alinhamento com os Estados Unidos, que procuraram aproveitar a instabilidade política da Colômbia para aumentar sua influência e sua presença militar na América do Sul.

O artigo oferece um painel de questões envolvidas nesse quadro complexo e original, na perspectiva de que a análise dessas questões possa favorecer a compreensão da interação entre elas nesse conjunto complexo. Além dessa seção introdutória, o artigo está dividido em quatro outras partes. A segunda discute as relações entre a persistência da violência política e o modelo institucional adotado. A terceira apresenta alguns elementos para a análise da chamada economia da droga, com estimativas de seu possível efeito em termos de ingresso de recursos externos no país. A quarta analisa a política de pacificação e fortalecimento do Estado do governo do ex-presidente Álvaro Uribe, chamada de "segurança democrática", com foco nas implicações fiscais dos gastos recordes com o setor de segurança. A quinta oferece um quadro sobre as consequências da violência e da "segurança democrática" no período recente. Seguem-se algumas notas finais.

\section{Violência Política e Fragilização do Estado}

A classificação da efetividade dos Estados pode ser feita por diversos critérios. A definição clássica e minimalista permite compará-los independentemente dos direitos historicamente adquiridos por seus cidadãos, como educação e saúde pública: um estado eficiente é o que tem domínio sobre um território definido e sobre sua população e detém o monopólio do uso legítimo da força. Por essa definição, a Colômbia poderia ser considerada um Estado fragilizado, por não ter controle sobre todo o território, parte do qual está sob o domínio de grupos civis armados e de traficantes, cidadãos que o Estado não controla e que disputam ou exercem de fato o monopólio da violência nessas áreas.

A classificação da Colômbia tende a melhorar com os recentes resultados anunciados pelo governo nas políticas de combate ao conflito armado e ao tráfico de drogas. Desde 1998, a postura adotada foi de enfrentamento direto e sem tolerância, com maior uso de operações militares e policiais e, de fumigamento aéreo de plantações de drogas, mudanças que fazem parte do fortalecimento da aliança com os Estados Unidos pelo Plano Colômbia. Uma política muito polêmica, cujos resultados, apesar de obtidos por meios e dados questionáveis, indicam o fortalecimento do Estado. Inegavelmente há uma melhora em comparação com as estimativas de um terço do território fora do controle nas décadas de 1980 e 1990.

Embora nessa época fosse possível defender a falência do Estado colombiano baseando-se nas falhas de segurança, esta pesquisa chama atenção para o fato de que em nenhum momento o Estado perdeu suas capacidades econômicas. Apesar de momentos de descontrole do câmbio paralelo, nunca houve perda de capacidade de desenvolver políticas econômicas nem perda de capacidade fiscal, como será detalhado na última seção.

O conflito armado interno tem raízes profundas na história colombiana, marcada pela desigualdade social e por uma política centralizada e oligopolista, controlada pelas elites descendentes dos colonizadores. O poder esteve por mais de um século, desde a independência em 1819 nas mãos de dois partidos políticos, o Liberal e o Conservador, 
que se alternavam no governo e chegaram a se enfrentar num confronto direto, conhecido como Guerra dos Mil Dias entre 1899 e 1902. É um tipo de regime que se encaixa na teoria dos custos de DAHL: quanto maiores os custos de aceitar a derrota, de se tornar oposição (altos em um regime centralizado e exclusivista), menores as chances de ser mantido um regime efetivamente competitivo e de serem respeitadas as regras do jogo democrático. Os altos custos de derrota fariam os perdedores partirem para o "tudo ou nada" político ou buscarem outras vias, extraoficiais, para manter o poder ou para tomá-lo para si. Pode também ser comparado com uma versão do chamado "jogo de soma zero", da teoria dos jogos, em que um ganho para um lado significa obrigatoriamente uma perda para seu oponente. É isso que se observa na história colombiana: conflitos diretos, fraudes eleitorais e o estabelecimento de milícias pelos latifundiários para manter o poder local e o controle sobre os camponeses.

Em 1948, o assassinato de um popular candidato à presidência que prometia mudanças sociais profundas, como direitos trabalhistas, marcou uma mudança no tom dessa relação política. A morte de Jorge Eliécer Gaitán, candidato dissidente do Partido Liberal, nunca teve mandante confirmado, mas a condenação generalizada do partido de maior oposição, o Partido Conservador, gerou um levante popular espontâneo e desorganizado que revolveu o país, conhecido como "El Bogotazo".

Esse levante espontâneo é apontado como o momento de diferenciação da história política colombiana em relação a outros países de regimes igualmente oligopolistas e centralizados. As eleições tiveram que ser adiantadas, a União Soviética foi apontada como instigadora, mas o prosseguimento da desordem e o surgimento das primeiras guerrilhas, foram as justificativas para a instalação de uma ditadura em 1953, que durou quatro anos. A ditadura foi substituída por um acordo entre os partidos tradicionais, Conservador e Liberal. Chamado de Frente Nacional, o acordo estabelecia a realização de eleições diretas, mas, independentemente dos resultados, eles se alternariam no governo do país.

Essa confirmação do desprezo à democracia incentivou ainda mais a busca por outras vias, já estimulada pelo modelo político, pela herança do passado e pela realidade da Guerra Fria, logo acompanhada pelo sucesso da Revolução Cubana. As guerrilhas se multiplicaram em várias regiões do país, com diferenças nos meios empregados e nas bases de apoio camponeses, estudantes, religiosos e sacerdotes influenciados pela Teologia da Libertação. Na década de 1960, vieram as reações às guerrilhas — milícias de latifundiários, grupos em disputa pelo controle territorial, vingadores. Conhecidos como paramilitares, esses grupos ganharam autonomia, contando muitas vezes com a anuência do Estado pelo objetivo comum de combater as guerrilhas.

Foi também nessa época que o sucesso da cocaína entre consumidores de classe média e alta, principalmente nos Estados Unidos, fez com que o relativamente pequeno cultivo de maconha colombiano fosse substituído por plantações de coca. Mais tarde, a descoberta do crack, variante de efeito mais potente, mais destrutivo, porém, mais barata, gerou uma demanda ainda maior para os traficantes de derivados da coca. A formação dos grandes cartéis de barões (Dons) da droga gerou mais violência, tanto nas áreas rurais como nas urbanas. A soma da violência partidária, dos cartéis, das guerrilhas, dos paramilitares e da 
repressão do governo gerou tamanha violência e instabilidade, que o período entre 1950 e meados dos anos 1960 ficou conhecido simplesmente como La Violencia.

Multiplicaram-se as violações aos direitos humanos por todos os atores desse conflito, inicialmente nas áreas rurais. A expulsão ou a fuga de camponeses tornou a Colômbia o país com o maior número de cidadãos "deslocados" (desplazados) no mundo. A estimativa de quantos colombianos são forçados a migrar pelo conflito varia muito entre as fontes: o governo divulga 3,7 milhões em 2011 (DEPARTAMENTO.., 2011), mas ONGs de defesa dos direitos humanos, como a CODHES (CONSULTORÍA..., 2011; ACNUR, 2011), asseguram que o número ultrapassa os 5 milhões. São números enormes, diante da população de 45,5 milhões de pessoas. Somam-se a isso as práticas de terrorismo e de sequestro de pessoas para obtenção de dinheiro no resgate ou para troca por prisioneiros, além de sequestro e compra de crianças para integrar tropas e de mulheres (ABADIA, 2008), usadas para trabalhos domésticos e sexuais ainda hoje.

Tornou-se constante a mescla entre as esferas ilegais e legais, oficiais e particulares da vida colombiana. A corrupção ou perseguição de políticos, jornalistas e magistrados se tornou rotineira. Um grande marco foi o assassinato em 1984 do Ministro da Justiça, Rodrigo de Lara Bonilla, que denunciara o chefe do cartel de Medellín, Pablo Escobar, que acabava de ser eleito suplente de um senador.

A fragilização da democracia aparece na alta taxa de abstenção, de 57\% nas eleições de 2010. O absenteísmo perdurou mesmo depois das campanhas de pluripartidarismo dos anos 1980 e da reforma constitucional de 1991, voltada para descentralização e reforço do papel social do Estado. É mostra da falta de confiança no processo político ou em sua capacidade de gerar mudanças, reflexo dos danos da violência e da corrupção no que Robert Putnan chamou de capital social, a cooperação e confiança existentes em uma sociedade em contraste com a valorização do particularismo e do patrimonialismo, já frequente na América Latina.

As políticas de combate ao tráfico e à violência política variavam desde "tolerância zero" e enfrentamento direto, até anistias e negociações diretas. Muitas vezes foram denunciadas alianças entre os grupos que se uniam contra um inimigo comum, como guerrilhas e narcotraficantes contra o governo, mais frequentemente entre governo e paramilitares, e até entre governo e narcotraficantes, como relata o juiz Walter Fanganiello Maierovitch (SILVA, 2010, p. 211 ) ao ser perguntado sobre por que Diego Montoya Sanchez, chefe do Cartel do Valle do Norte, da Colômbia, não era preso:

[...] porque ajuda a combater as FARC e ainda impede que elas conquistem uma área rica em petróleo no Oeste da Colômbia. A política antidrogas é uma política interesseira, que esconde objetivos geoestratégicos. [...] Ele tem uma situação particular, porque apoia e é apoiado pelos grupos paramilitares de direita que combatem as FARC, grupo guerrilheiro esquerdista (CAPRIGLIONE e CAMARANTE, 2007).

\section{A Economia da Produção e do Tráfico de Drogas na Colômbia}

A produção e o tráfico de drogas geram efeitos econômicos relevantes na Colômbia: de um lado, trata-se de receita cambial considerável, com importante efeito multiplicador 
interno; de outro, representam um problema para a imagem e para o ambiente de negócios, o que pode afetar o investimento externo. Há também a questão da ajuda externa para o combate à droga e dos efeitos do gasto militar sobre as políticas públicas.

A avaliação dos efeitos cambiais da droga enfrenta dificuldades, em especial no que se refere à estimação dos montantes internalizados pela rede de traficantes. A constatação de que a Colômbia atravessou as últimas décadas do século XX com posição cambial bem mais folgada que os demais países da região é um indício de elevada entrada de dólares.

É certo que houve outros fatores favoráveis para esse bom desempenho externo. Um deles é a chamada "bonanza cafetalera" gerada em 1975, quando a forte geada no Brasil elevou os preços do café, de pouco menos de US $\$ 75$ por libra para mais de US $\$ 225$ por libra, e uma boa safra colombiana aumentou as receitas de exportações e permitiu a acumulação de reservas expressivas (CONSELHO..., 2005). Os preços mantiveram-se elevados até meados da década seguinte, ou seja, durante os piores anos da crise da dívida externa. Foi também nessa época que a Colômbia voltou a explorar minérios, foram descobertas novas jazidas de petróleo, o que reforçou as receitas fiscais e atraiu mais crédito e investimentos externos (Fig. 1), e a Colômbia firmou acordos de cooperação no combate às drogas com os Estados Unidos, o que garantia acesso a financiamentos e facilitava a obtenção de crédito internacional.

Fig. 1: Investimento estrangeiro na Colômbia

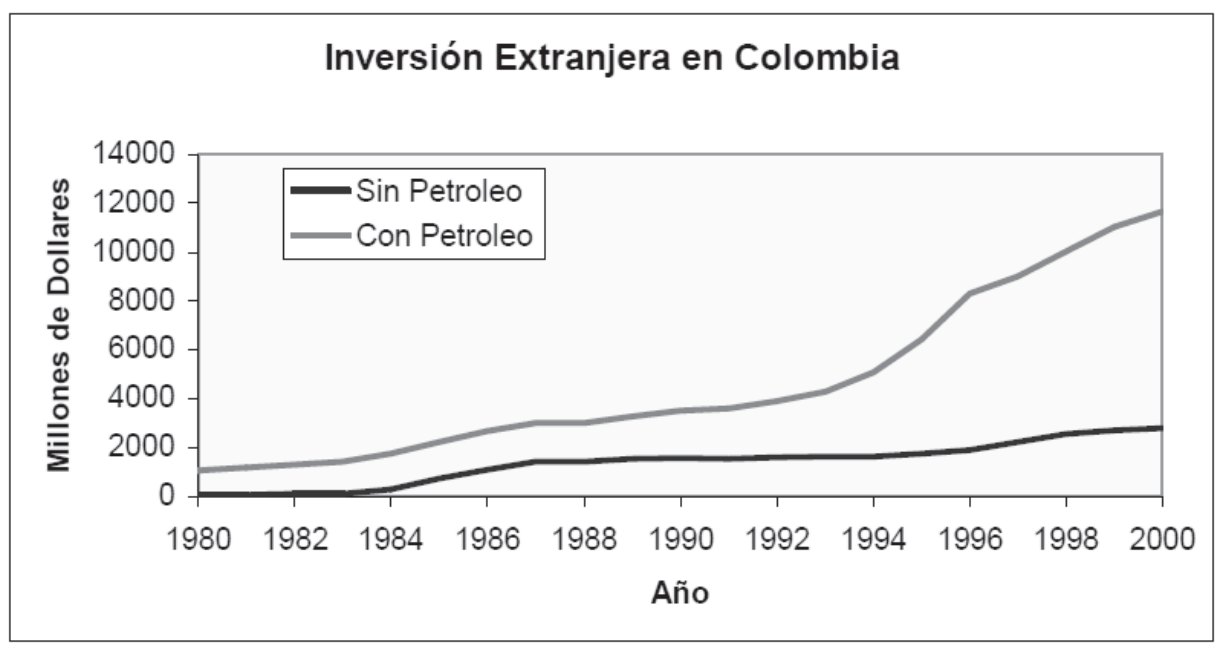

Fonte: Márquez-Escobar, 2011.

Ainda assim, as receitas cambiais da droga são muito elevadas, como pode ser verificado por algumas estimativas, sujeitas evidentemente a imprecisões consideráveis.

A ONU apontou movimentação mundial de US $\$ 50$ bilhões pelo tráfico de cocaína em 2008, sendo metade da Colômbia, US\$ 25 bilhões (INCB, 2011). Para KOPP (1998), menos de $1 \%$ do valor final fica com os plantadores, camponeses forçados pelos traficantes a cultivar coca ou incentivados a fazê-lo pelo baixo rendimento de outras culturas. Trata-se de valor irrisório. A partir dessa etapa inicial, as estimativas são menos precisas, com divergências acentuadas e pontos desconhecidos. 
Há estimativas de que entre $25 \%$ e $50 \%$ do valor ficam com a cadeia doméstica de elaboração e transporte da pasta base e o restante cabe aos que transportam a droga para o exterior e aos distribuidores no país de destino. Pode-se então supor que entre $50 \%$ e $75 \%$ (INCB, 2011) do valor da droga são pagos a agentes que operam no exterior (entrega no país consumidor e distribuição local).

Muitos desses agentes no exterior são traficantes colombianos, ou residentes na Colômbia, com interesse em "lavar" parte do dinheiro e remetê-lo para o país de origem da droga, enquanto outra parte é mantida em paraísos fiscais, podendo ser remetida para a Colômbia a depender das circunstâncias. Pode-se estimar que, dessa receita por "serviços da droga no exterior" recebida por colombianos ou residentes na Colômbia, metade é internalizada no país e a outra metade é mantida no exterior.

Chega-se assim ao cálculo de que, da receita total, entre $25 \%$ e $50 \%$ são pagos no país (plantadores, processadores e transportadores locais) e, dos outros $50 \%$ a $75 \%$, uma parte é enviada para a Colômbia e outra é mantida no exterior.

Com esses parâmetros, partindo da receita de US\$ 25 bilhões, podem ser estimados:

— pagamentos por produção e serviços internos: entre U\$6,25 bilhões e U\$ 12,5 bilhões (25\% a $50 \%$ do total);

— ingresso de receitas por pagamento de serviços no exterior: entre US\$ 3,12 bilhões e US\$ 4,68 bilhões (metade dos 50\% a 75\% referentes a serviços no exterior);

— ingresso total por ano: entre US\$ 9,37 bilhões e US\$17,2 bilhões.

Isso significa algo entre 3,8\% e 7,0\% do PIB da Colômbia em 2008, US\$ 245,5 bilhões, números muito expressivos sob qualquer critério.

Acrescente-se que o valor acumulado no exterior por traficantes colombianos ou residentes na Colômbia é uma reserva considerável que pode ser repatriada, a depender de estímulos ou de mudanças na avaliação sobre as vantagens de manter o dinheiro fora ou trazê-lo para o país.

A particularidade colombiana em relação à distribuição padrão de ganhos do tráfico de drogas, em que boa parte é internalizada, é que até 1991 (INCB, 2011 ) não havia leis específicas contra lavagem de dinheiro. Havia apenas referências vagas a enriquecimento ilícito. O grau de corrupção e de infiltração dos cartéis da droga na política e na justiça foi enorme e, em alguns períodos, o próprio governo autorizou a entrada de dinheiro sem origem justificada, ao abrigo de "anistias", o que permitia não só repatriar dinheiro como também lavar o dinheiro que estivesse ilegal no país.

A primeira dessas anistias ocorreu durante o mandato de Alfonso Lopes Michelson, presidente de 1974 a 1978, com o mecanismo vulgarmente chamado de "abrir la ventanilla siniestra": permitir a entrada de dinheiro sem origem declarada e com perdões fiscais para investimentos no país, ou apenas para compra de títulos do governo. Era uma fonte alternativa de reserva de divisas ou de financiamento de gastos estatais, uma apropriação direta de dinheiro de origem muito suspeita. 
O mecanismo foi usado por outros governos, destacadamente o de Belisário Betancour de 1982 a 1986, sobre o qual um traficante preso deu seu relato:

Yo no niego (...) que estamos hoy disfrutando de una amnistía tributaria, que prácticamente podría haber "enfriado" los dineros que ellos llaman "calientes". O sea que hoy están legalizados más que nunca. Ese dinero fue traído al país cuando no existía una amnistía tributaria, pero gracias a la apertura democrática $(s i c)$ y a la amnistía tributaria (de Betancur) es completamente legal. (Lehder Rivas, narcotraficante colombiano) (NIZKOR, 2011).

Tamanhas facilidades fazem crer que, no caso colombiano, grande parte da renda obtida com tráfico era repatriada, com impacto significativo na economia. É de se destacar que o período de maiores anistias tributárias coincidiu com o período de escassez de crédito internacional, a crise da dívida externa da América Latina nos anos 1980.

É de se supor que, sem anistias e mecanismos legalizadores, a afluência de dólares ilegais teria sido bem menor. Durante diversos períodos da década de 1990, com o câmbio ainda fixo, o mercado paralelo de dólares chegou a ser mais barato que o oficial (THOUMI, 2003). Isso aponta para a constância da entrada de dinheiro ilegal pelo mecanismo que a DEA, Drug Enforcement Administration, o órgão de combate às drogas dos Estados Unidos, definiu como "o maior mecanismo de lavagem de dinheiro de drogas do hemisfério ocidental" (GUILLÉN, 2000). Esse mecanismo baseia-se na associação de detentores de dólares ilegais com importadoras. As importadoras usavam os dólares ilegais, livres de taxas e restrições de conversão do governo, para importar com menores custos, e pagavam aos criminosos com pesos colombianos "limpos", gerados pela venda dos importados (LAYTON, 2011).

Além de ser fonte de reservas, o dinheiro do narcotráfico circula pela economia colombiana causando diferentes impactos. $\mathrm{Na}$ base da produção, com a baixa remuneração dos camponeses, a única vantagem diante dos custos da violência e dos deslocamentos forçados seria a diferença de rendimento diante de cultivos legais e a obtenção de emprego.

Em 1990, estimou-se que uma parcela de cerca de 3\% da população rural colombiana se encontrava envolvida na produção de coca (INCB, 2011), número relevante para a economia local de algumas regiões. É nessa etapa da produção que se concentra boa parte dos esforços de combate do governo colombiano e dos Estados Unidos, com o plano Colômbia, com fumigamentos aéreos com pesticidas, muito polêmicos por contaminarem grandes áreas pouco precisas, e, mais recentemente, com incentivos para a troca de plantio. Vale destacar que o valor de toda a plantação de coca e ópio do mundo não alcança $2 \%$ do total mundial destinado à assistência ao desenvolvimento (U\$ 57,3 bilhões), o que indica que com muito menos seria possível um combate mais eficaz se o foco do combate fosse superar a fragilidade econômica que induz a população dessas regiões a se dedicar a esses cultivos (INCB, 2011).

A economia paralela está praticamente toda nas mãos dos traficantes, e esses têm um padrão de gastos ostensivo que pouco contribui para a economia do país. Gastam com terras (aumentando a concentração fundiária), produtos importados, empreendimentos imobiliários e empresas que possam praticar superfaturamento e mascarar as origens do dinheiro. Pelo tipo de atividade desenvolvida, supõe-se que a receita da droga, apesar de elevada, tenha fator de multiplicação social pequeno, cerca de 1,55 (INCB, 2001). 
Entre 1997 e 2000, a crise gerada pelo descontrole do orçamento governamental e o maior endividamento da população coincidiu com enorme aumento da produção de drogas alcançando o maior nível da história (Fig. 2).

Fig. 2 - Cultivo de Coca na região dos Andes, 1988-2008

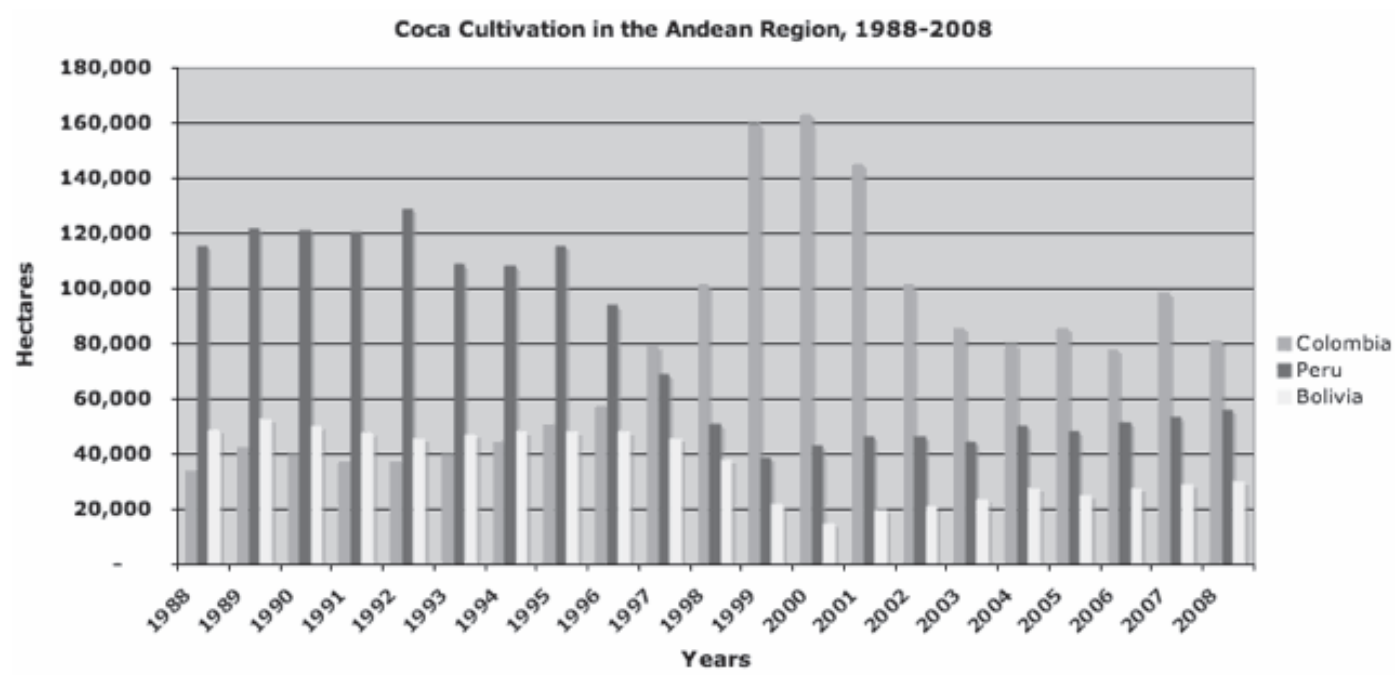

Source: 1988-1998 data: State Department Intemational Narcotics Control Strategy Reports; $1999-2008$ data: UNODC

Fonte: JUST..., 2009.

\section{Gasto Militar, Política Fiscal e Financiamento da "Segurança Democrática” no Governo Uribe}

O gasto público no governo de Álvaro Uribe atingiu o índice mais alto da história da Colômbia, com forte influência dos gastos militares, diretamente relacionados com a política de "segurança democrática", instituída no início do seu mandato em 2002, com o objetivo de recuperar a segurança nacional e o controle de todo o território do país. Esses gastos foram financiados de início com base na melhora do quadro fiscal graças ao desempenho econômico favorável e posteriormente levaram à criação de novos tributos.

Apesar de o conflito armado interno da Colômbia estar em curso há mais de sessenta anos, foi nas administrações de Andrés Pastrana e Álvaro Uribe que a agenda política e econômica do país foi mais direcionada à resolução do conflito. Nesse contexto, surgiu o Plano Colômbia, em 1998. Apresentado como componente essencial da guerra dos Estados Unidos contra as drogas na América Latina, com orçamento inicial de US $\$ 1,3$ bilhão (STOKES, 2006, p. 270). Concebido de início como um projeto de investimento e reabilitação das zonas de conflito e de cultivos ilícitos, o plano privilegiou a repressão das plantações de coca.

De 1999 a 2002 a Colômbia recebeu grande volume de crédito, o que gerou um crescimento ainda maior da dívida externa do país (GORDILLO, 2008, p. 311 ). Em 2003, um programa do governo Bush, Iniciativa Regional Andina, destinou outros US\$ 538 milhões para o Exército colombiano. O plano trouxe mais endividamento, militarização, 
danos ao meio ambiente, violações de direitos humanos, interferência norte-americana, instabilidade com os vizinhos, violência em nome da paz e prosperidade e maiores dificuldades para a ascensão de outras forças políticas ao poder.

Ninguém duvida que a política de "Segurança Democrática" é o carro chefe da administração de Uribe, e, se são analisados os dados do governo nos demais aspectos, com certeza a conclusão seria que este programa tem sido o único. O gasto militar, que representava na década de 1990 2,4\% do PIB, passou a representar 4,8\% em 2008, e entre 2000 e 2005 cresceu por volta dos $78,4 \%$, o que faz com que a Colômbia seja considerada como um dos países detentores do maior gasto no setor. (SANABRIA DUQUE, 2009, tradução própria.)

A Colômbia é considerada um dos países mais militarizados do mundo e um dos que mais têm aumentado seu gasto nos últimos tempos: depois de alguns picos nas décadas anteriores (Fig. 3), o gasto de defesa foi de aproximadamente 4,7\% do PIB entre $2001 \mathrm{e}$ 2007 (Fig. 4), bem acima da média da região, 1,6\% do PIB no mesmo período. Em relação aos demais países em conflito, de acordo com a pesquisa, a Colômbia apenas foi superada por Israel (8,7\%) e Burundi (6,3\%). De conformidade com o controlador geral Julio Cesar Turbay, esses números se relacionam com o fato de que aproximadamente $80 \%$ dos funcionários públicos fazem parte do setor de defesa (GASTO MILITAR..., 2008).

Há muitas discussões sobre o tamanho do gasto militar realizado pelo governo colombiano. Os gastos com defesa e segurança são difíceis de contabilizar e a realização de estimativas é complexa, pela escolha de variáveis a considerar e a variedade de custos que podem estar associados ao conflito armado. Acrescente-se que, em 2008, o DANE realizou mudanças metodológicas no cálculo das contas nacionais, que passaram a ter como base o ano 2000, e não mais 1994, e alteraram os valores nominais do PIB, que tiveram crescimento significativo, de 18,6\% (MINISTERIO..., 2009).

Fig. 3 - Colômbia - Gasto de defesa como \% do PIB - 1926-1998

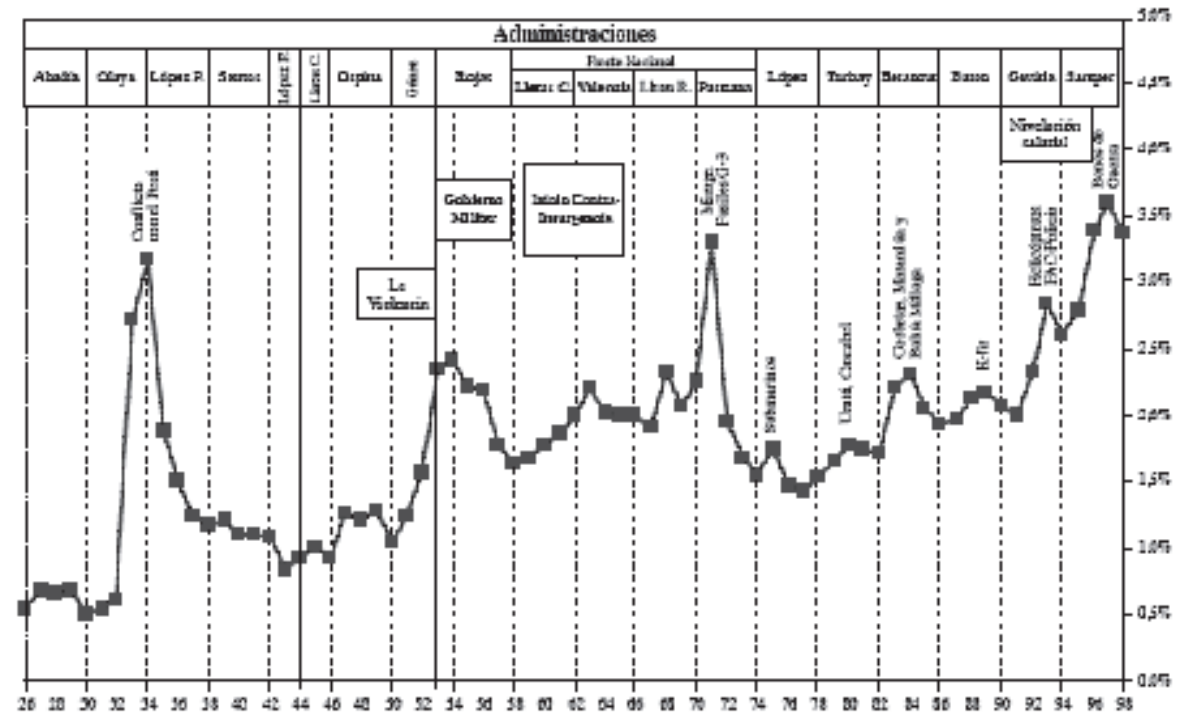

Fonte: TOBAR, REYES Y VELASCO, 1998. 
Fig. 4 - Colômbia - Orçamento do setor de defesa como \% do PIB (1) (1995-2009)

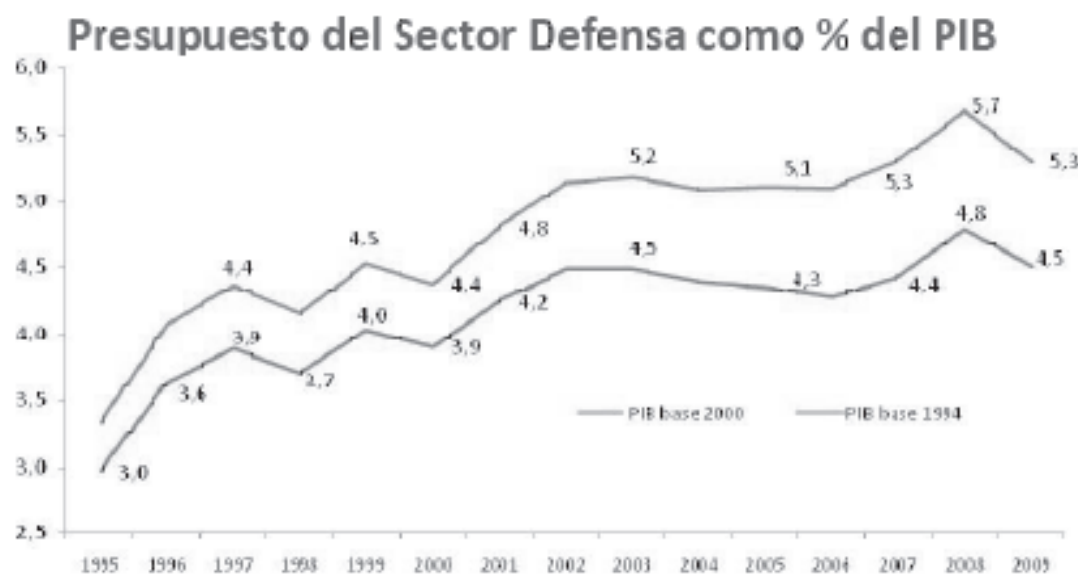

Fonte: Ministerio de Defensa Nacional, 2009

O gasto com defesa cresceu de forma contínua e expressiva entre 1990 e 2008. A partir de 2003, o crescimento foi mais expressivo, - de $2,2 \%$ do PIB para $4,8 \%$ do PIB em 2008. A partir de então, essa cifra tem permanecido próxima aos $5 \%$ do PIB, de acordo com a nova base de cálculo do Departamento Administrativo Nacional de Estadística e com os dados disponibilizados pelo Ministério da Defesa. O aumento foi financiado inicialmente pelo aumento da arrecadação tributária que acompanhou a bonança econômica do país, sem a criação de impostos extraordinários ou alocação de recursos em detrimento de outras despesas. O orçamento de defesa permaneceu entre 13 e $14 \%$ do orçamento total entre 2002 e 2007 (salvo o serviço de dívida), aumentando para 15,6\% apenas em 2008 e a 15\% em 2009 (MINISTERIO..., 2009).

Para continuar o financiamento da política de "segurança democrática", contudo, o governo, alegando a necessidade de medidas mais eficazes para promover a paz, instituiu um imposto específico denominado, primeiramente, como imposto para a "segurança democrática" em 2002, e, a partir de 2004, também o imposto ao patrimônio, não apenas como complemento do imposto de renda para proporcionar crescimento econômico, como foi no primeiro momento da sua existência entre 1934 e 1992, mas também como forma de gerar recursos para financiar a nova política pública de segurança. Após várias discussões em 2009, o Congresso aprovou a vigência do tributo pelo menos até o ano de 2014.

No que se refere à existência de recursos para o financiamento dos gastos com defesa e segurança, as declarações do ministro da defesa muitas vezes são contraditórias. Por exemplo, de acordo com um artigo publicado no jornal "El espectador" da Colômbia, em maio de 2009, ou seja, antes da aprovação da continuidade da vigência do imposto sobre o patrimônio, em um primeiro momento, quando questionado sobre a necessidade de um novo imposto para financiar a política de "Segurança Democrática", o então ministro Juan Manuel Santos, atual presidente da República, afirmou que seria cedo pensar em um novo imposto, pois as necessidades orçamentárias seriam menores do que as do momento em que foi instituído o tributo, não sendo preciso manter o mesmo ritmo de investimentos (FUERZAS ARMADAS..., 2009). 
Já de acordo com um documento publicado em julho do mesmo ano pela Fundación para la Educación Superior y el Desarrollo intitulado de "El financiamiento de los gastos en defensa: un debate importante", Santos diz cogitar a necessidade de financiamento a longo prazo dos gastos excepcionais que a Colômbia fora obrigada a assumir pela "segurança democrática" (PERRY, 2009).

Logo, o governo declarou considerar que o imposto sobre o patrimônio deveria ser mantido, ou então outro tributo deveria ser criado para substituí-lo, não para aumentar o gasto com defesa, já que se projeta um crescimento muito baixo para tal setor, mas sim para compensar o mau rendimento esperado da arrecadação tributária em geral, como consequência da recessão originada pela crise econômica mundial e de vários privilégios tributários concedidos nos últimos anos — problema antigo da política fiscal colombiana e que requer uma reforma estrutural (PERRY, 2009).

\section{Resultados e Consequências da "Segurança Democrática”}

A respeito dos gastos militares realizados pelo governo, os dados revelados ainda não dão total clareza tanto sobre a utilização dos recursos como de resultados práticos em relação à segurança. Porém, de acordo com uma declaração do ministro da defesa, os 8.3 bilhões de pesos colombianos, aproximadamente 4.1 bilhões de dólares, arrecadados pelo imposto sobre o patrimônio já foram aplicados na sua maioria e apenas faltaria completar o número de homens da polícia e das forças armadas. Do orçamento para a segurança e defesa, $70 \%$ dos recursos foram utilizados para investimentos pontuais como a aquisição de equipamentos de mobilidade e renovação de armamento. Além disso, o imposto sobre o patrimônio foi utilizado para ativas novas unidades militares especializadas (FUERZAS ARMADAS..., 2009).

Durante os últimos dez anos, o investimento em defesa cresceu em média 3,2\% anual real e dará um salto importante para crescer 35,7\% durante o período entre 2008 e 2011, utilizando os recursos extraordinários da lei 1111 de 2006, a qual instituiu uma série de reformas tributárias. Nesse mesmo período os gastos com pessoal crescem entorno de $6,1 \%$ e 3,7\% real anual e os gastos gerais $10,8 \%$ e $3,4 \%$ real anual. (FUERZAS ARMADAS..., 2009.)

As projeções para 2012, de acordo com o ministério da defesa, supõem a necessidade de manter o atual contingente para garantir e consolidar a recuperação do controle do territorial nacional e os gastos com pessoal e os gastos gerais deverão manter os mesmos valores em termos reais. Pelas cifras do governo, entre 2000 e 2008, os sequestros diminuíram $87 \%$; os atentados terroristas, $78 \%$; a pirataria terrestre, $33 \%$; e os homicídios, $39 \%$. A melhoria dos índices de segurança contribuiu diretamente para o país aproveitar a conjuntura externa favorável para atingir um período positivo em relação ao investimento privado que, segundo os dados oficiais, passou de $13,1 \%$ a $23,7 \%$ do PIB entre 2000 e 2008 , ademais de altas taxas de crescimento econômico entre 2003 e 2008 (FUERZAS ARMADAS, 2009).

Para a análise dos custos do conflito, a principal referência é o modelo desenvolvido pelos autores TRUJILLO e BADELL (1998), que dividiram os custos em diretos - perda 
de capital físico natural e humano que afetam toda a sociedade - e indiretos - aqueles que não afetam de forma direta os recursos, mas que representam um custo de oportunidade ou a perda de bens e fatores de produção. Para ALVAREZ E RETTBERG (2008, p. 14-37), os custos indiretos são os que possuem maior impacto, pois atingem toda a sociedade.

No caso colombiano, se analisados os gastos militares, é evidente que os custos em relação ao conflito armado interno não se impõem apenas aos setores e às pessoas diretamente afetadas, já que viver em um ambiente impregnado de violência representa em si custos substanciais e reais. Sendo assim, ainda que a Colômbia seja um dos poucos países latino-americanos que tenha mantido um crescimento constante da economia nos últimos cinco anos, é fato que a existência do conflito armado interno tem repercutido no desempenho econômico do país.

Igualmente, muitos investimentos que o Estado poderia realizar em educação e em saúde acabam prejudicados pelo esforço intensivo em destinar recursos aos setores de segurança e defesa, o que denuncia uma estratégia política de priorizar a luta contra o chamado terrorismo - termo utilizado pelo governo para designar conflito armado.

Um estudo realizado pelo PNUD (Programa das Nações Unidas para o Desenvolvimento) indica que o conflito colombiano tem gerado um efeito negativo sobre a receita da população. Segundo o estudo, em decorrência do conflito, a Colômbia tem perdido $17 \%$ da sua receita per capita nos últimos dez anos. Isto é, [...] o dinheiro desperdiçado a cada ano corresponde a umas 4,6 vezes o que custam os programas de lares comunitários de bem-estar, os lares infantis e os restaurantes escolares da rede de apoio social. (PNUD 2003, p. 84.)

É muito importante ressaltar que, em uma situação de conflito, os cálculos referentes a suas conquistas e consequências é uma tarefa delicada, já que existe muita desinformação de todos elementos que dele fazem parte; várias diferenças metodológicas e de validade dos métodos de coleta de informação. Portanto, é considerado quase que inevitável a existência de erros ou manipulação dos resultados.

De acordo com PRADA (2008), em um conflito, os números fazem parte da guerra. No caso da Colômbia, esses números compreendem, por parte do governo, a quantidade de guerrilheiros mortos, capturados ou desmobilizados; as ações exitosas; a ocultação de dados que prejudiquem a própria administração, como os assassinatos políticos, torturas, desaparecimentos, ameaças, crimes extrajudiciais, refugiados, ações das guerrilhas, além de mortos e feridos das Forças Militares e da Polícia Nacional. Por outro lado, as guerrilhas também desinformam, exageram suas cifras de ações e abatimento com relação ao exército, minimizam seus sequestros e chantagens.

Um exemplo disso, a que se refere Otero, é o caso do informe do governo sobre os guerrilheiros:

De acordo com a informação do Ministério da Defesa, de 1976 a 2007, cerca de 76.700 guerrilheiros ficaram fora de combate por mortes, deserções ou capturas. $\mathrm{O}$ que surpreende nessas cifras é que 52.509 guerrilheiros desse total correspondem ao intervalo de tempo entre 2002 e 2007 . Ou seja, que durante esses seis anos a taxa de 
substituição de guerrilheiros foi extraordinária, já que em 2007, de acordo com fontes oficiais, havia 15.000 homens em armas, o que significa que ou os números estão supervalorizados ou que as guerrilhas possuem uma capacidade de captação de efetivos. [...] (PRADA, 2008, p. 18.)

Otero ainda afirma que os desaparecimentos, as torturas e as ameaças tendem a ser superiores ao registrado, pelo medo da população de denunciar. É fato que as mortes em combate tanto dos guerrilheiros quanto dos paramilitares são difíceis de contabilizar com exatidão, já que os cadáveres quase nunca aparecem. Pode-se afirmar que, em geral, os números referentes ao conflito tendem a ser incertos, subestimados ou manipulados, fazendo a realidade mais cruel do que parece ser.

Sendo assim, a dinâmica acelerada dos gastos com defesa e segurança é passível de vários questionamentos sobre sua eficiência e sustentação. Apesar de o governo sempre apresentar dados positivos em relação à política de "segurança democrática", sua credibilidade muitas vezes é abalada por fatos que indicam violações dos direitos humanos, como os casos de falsos positivos, execuções extrajudiciais e detenções massivas. Esses elementos ocorrem com certa frequência, de modo que não é possível identificá-los como fatos isolados.

Nesse cenário, o paramilitarismo se posiciona como ator circunstancial dentro do conflito. Os paramilitares são grupos de mercenários financiados substancialmente pelo narcotráfico e por aqueles que pagam pelo serviço de proteção; conhecidos também como grupos de autodefensas que fazem o trabalho considerado "sujo" do exército, para que o Estado não seja questionado. Para isso, usam de violência para combater as bases dos grupos insurgentes armados, assim como, qualquer tipo de manifestação de inconformidade social, causando danos à população civil. Entre as suas operações ilegítimas, estão execuções, massacres, intimidação e deslocamento forçado da população civil pelo esvaziamento de zonas de conflito, entre outras.

O governo Uribe realizou um processo de paz com as principais organizações paramilitares que levou à suposta desmobilização desses grupos. Seus principais chefes foram extraditados aos Estados Unidos em decorrência dos vínculos com o narcotráfico. No entanto, posteriormente, foi comprovado que o processo de desmobilização havia sido burlado e que, atualmente, diversos grupos continuam ativos mantendo em distintas regiões seus laços políticos e militares. O governo não reconhece o fracasso deste processo de paz e, consequentemente, denominou as estruturas paramilitares vigentes como "bandas criminais emergentes", mais conhecidas como BACRIM.

\section{Notas Finais}

O fortalecimento recente do Estado colombiano, expresso na redução da capacidade operacional dos grupos guerrilheiros e no aumento do controle sobre o território nacional e sobre a população, foi muito favorecido pela capacidade de ampliar o gasto militar e de financiá-lo pelo aumento de impostos. A estabilidade econômica foi crucial para tanto, o que comprova a relação peculiar entre o desempenho econômico e a presença de problemas 
típicos de Estados apontados como fragilizados ou falidos. Na Colômbia, esses problemas conviveram com um Estado forte e não impediram seu fortalecimento e a ampliação de suas capacidades. Contudo, os êxitos alcançados estão longe de equacionar efetivamente esses problemas. Os episódios de parapolítica, ou seja, revelação de vínculos de políticos com paramilitares, ocorrem com frequência, o que gerou escândalos de proporções internacionais para o governo de Uribe. Na sua maioria, eles se relacionam com os casos de financiamento de campanhas políticas por parte do narcotráfico ou com os casos chamados de falsos positivos, em referência à expressão "positivo" da polícia, que designa uma operação exitosa quando de fato não é, em que civis pertencentes à classe menos favorecida economicamente são assassinados e vestidos com uniforme de guerrilheiros para fazerem parte das estatísticas de abatimento de integrantes de grupos insurgentes, ou ainda pela recompensa financeira oferecida pelo governo por deter ou eliminar subversivos.

Em 2002, houve mais de oito mil assassinatos políticos na Colômbia, 80\% dos quais realizados por grupos paramilitares aliados ao exército colombiano. Ainda que os Estados Unidos tivessem "promovido a poliarquia" na América Latina em geral, apoiando-se mais no consenso que na coerção para manter seu domínio, na Colômbia apoia tenazmente um Estado que de modo primário recorre ao terrorismo de Estado para destruir o dissenso e as pressões populares em prol de reformas. Enquanto os Estados Unidos continuem subscrevendo e apoiando este terrorismo de Estado, poderia se dizer com justiça - sem minimizar o papel da classe dominante colombiana neste processo - que "promove a terrorcracia" na Colômbia. (STOKES, 2006, p. 266.)

A estratégia de combate ao conflito armado baseada no terrorismo de Estado acaba não fazendo distinção entre os combatentes e não combatentes, o que ocasiona a morte ou ferimento de muitos civis e o deslocamento forçado de pessoas. A população civil tem sofrido as consequências da chamada guerra contra o terror assumida pelo governo colombiano em parceria com os Estados Unidos. O medo faz parte do cotidiano dos cidadãos que temem sem distinção os atores da confrontação armada. A liberdade de expressão e outros direitos básicos foram restringidos pelo governo, ainda que de forma dissimulada, ou seja, os cidadãos se veem limitados a criticar a administração no poder, porque podem ser apontados como terroristas ou perturbadores da ordem.

Desse modo, a sensação de maior segurança descrita por uma parte da população é superficial e impera a liberdade vigiada pelo Estado que instaura o medo como forma de legitimar-se. Por isso, talvez seja relevante enfatizar o que disse Todorov a respeito de uma sociedade totalitária: "Na sociedade totalitária, o grupo dirigente (o partido) exerce sua própria autonomia, mas aliena inteiramente a dos cidadãos comuns: o indivíduo vive na crença de uma punição proveniente do Estado onipotente" (TODOROV, 1999, p. 239).

A política de "segurança democrática", cuja premissa universalista é promover segurança a todos da mesma forma, independentemente da sua filiação política, não é condizente com várias experiências e dados observados. As estratégias de combate ao conflito armado são baseadas na política de guerra ao terror, de violência de Estado e de negação das verdadeiras origens do conflito. 
De forma significativa, a "guerra contra o terror" e as guerras civis contemporâneas compartem muitas das mesmas dinâmicas. Algumas destas semelhanças parecem ser inerentes a ideia em si de "guerra" e a legitimidade que habitualmente outorga a diversas formas de violência. Outras similitudes representam o ato de que forças globais análogas têm ajudado a dar forma tanto as guerras civis contemporâneas como a atual "guerra contra o terror". (KEEN, 2007, p. 3.)

Esse método de utilização da violência na defesa da ordem e da paz faz parte de uma tendência cada vez mais frequente assumida como legítima pelo Estado no combate a qualquer ameaça. Atitude que alimenta substancialmente o terror além de gerar impasses, já que a maioria dos crimes de terror cometidos pelo Estado não são assumidos por sua qualidade de instituição sui generis, ou seja, sua posição acima dos indivíduos como portador do bem comum, da racionalidade e do equilíbrio.

Enquanto a ideia de "guerra contra o terror" legitima a violência com a etiqueta de guerra, o status de "prisioneiro de guerra" tem sido renegado ao "outro lado". Assim, estamos convidados a acreditar que simultaneamente é uma guerra e não o é. Isto reflete a esquizofrenia do discurso oficial em muitas guerras civis onde o Estado torna ilegítima a violência rebelde tratando-a como "criminal", enquanto legitima a sua própria qualificando-a de "guerra". (KEEN, 2007, p. 3.)

Em meio a uma situação de instabilidade, é fundamental pensar nos meios e fins da violência, avaliar motivações e causas do conflito. Ainda quando, o conflito tenha, no início, sido configurado pelas guerrilhas partidárias, o governo preferiu reprimir os grupos de revoltados em vez de tentar entender as causas do conflito, este que com o tempo foi adquirindo outras configurações e modificando-se pelo surgimento de novos atores e demandas, atingindo uma magnitude insustentável. Porém, a saída a toda essa guerra que se configurou no país poderia acabar se ambas as partes, tanto o governo como grupos armados, se propusessem a chegar a um acordo por meio da negociação e do intercâmbio humanitário, o que implicaria perdas e ganhos aos dois lados. No entanto, parece coerente a afirmação de alguns sequestrados libertados pelos grupos guerrilheiros de que o conflito armado pode estar alimentando os interesses particulares que ambos os lados possuem na preservação da guerra (CONGOTE, 2009).

Nesse cenário, os grupos armados considerados ilegais ainda não perderam suas forças a ponto de serem forçados a um processo de paz. Enquanto isso, a estratégia de guerra contra o terror, adotada pelo Estado colombiano e apoiada pelos Estados Unidos, em conjunto com os grupos paramilitares, continua propagando a violência, o medo, a insegurança, a desigualdade social, ou seja, fatores que contribuem para o sofrimento ainda maior da população civil colombiana.

\section{RefERÊnCIAs Bibliográficas}

ABADIA, Laura. Studying Colombian armed Conflict from a Gender Perspective, paper para a Sciences Po Paris, Poitiers, 2009. 
ACNUR — Alto Comisionado de las Naciones Unidas para los Refugiados. Bogotá. Disponível em: <http://www.acnur.org/t3/operaciones/situacion-colombia/desplazamiento-interno-encolombia/> Acesso em: 2011.

ALVAREZ, Stephanie e RETTBERG, Angelika. Cuantificando los efectos economicos del conflicto: una exploración de los costos y los estudios sobre costos del conflicto armado colombiano. Colombia Internacional. 2008: p. 14-37.

CAPRIGLIONE, L. e CARAMANTE, A. (2007). Para juiz, entregar traficante aos EUA é subserviência atroz. Jornal Folha de S. Paulo, p. C-5, 3 set.

CEPAL. Disponível em: <http://www.eclac.cl/publicaciones/SecretariaEjecutiva/7/lcg2067/ gihaesp.pdf> Acesso em: set. 2011.

CONGOTE, Bernardo. Paramilitarismo y 'seguridad democrática' en Colombia. Bogotá, Le Monde Diplomatique Colombia, 81. Disponível em: <http://eldiplo.info/mostrar_articulo.php?id=947\&> Acesso em: 5 jan. 2010.

CONSELHO INTERNACIONAL DO CAFÉ - ICC. Salvador, nonagésima quarta sessão, "Volatilidade dos preços do café". Disponível em: <http://www.ico.org/documents/icc94-5p.pdf> Acesso em: 2005.

CONSULTORÍA PARA LOS DERECHOS HUMANOS Y EL DESPLAZAMIENTO CODHES. Disponível em: <http://www.codhes.org/index.php?option=com_docman\&task= cat_view\&gid=39\&Itemid=51> Acesso em: 2011.

DAHL, Robert. Poliarquia. Universidade de São Paulo, p. 37.

DEPARTAMENTO ADMINISTRATIVO NACIONAL DE ESTADÍSTICA, Censo General 2005. Disponível em: <http://www.dane.gov.co/files/censo2005/PERFIL_PDF_CG2005/ Oo000T7ToOo.PDF $>$.

FUERZAS ARMADAS INCORPORARÁN SEIS MIL HOMBRES CON IMPUESTOS DE GUERRA. Bogotá, El Espectador, 13 maio 2009. Disponível em: <http://www.elespectador.com/ noticias/judicial/articulo140633-fuerzas-armadas-incorporaran-6-mil-hombres-impuesto-deguerra> Acesso em: 6 jan. 2010. Tradução do autor.

GASTO MILITAR EN COLOMBIA, EL MÁS ALTO DEL CONTINENTE. Bogotá, El Espectador, 15 abr. 2008. Disponível em: <http://www.elespectador.com/noticias/negocios/articulo-losultimos-seis-anos-gasto-militar-represento-el-47-ciento-del-pib> Acesso em: 4 jan. 2010.

GORDILLO, Ernesto Moreno. El conflicto armado interno en Colombia. Bogotá: Ediciones Sem, 2008. p. 311.

GUILLÉN, Edward. Statement Before the House Subcommittee on Criminal Justice, Drug Policy, and Human Resources, June 23, 2000. Washington, DEA- Drug Enforcement Administration. Disponível em: <http://www.justice.gov/dea/pubs/cngrtest/cto6230o.htm>.

INCB - International Narcotic Control Board. Viena, Illicit drugs and economic development. Disponível em: <http://www.incb.org/pdf/e/ar/2002/incb_report_2002_1.pdf> Acesso em: 2011.

JUST THE FACTS. "UNODC 2008 coca data for the Andean Region”. Disponível em: <http:// justf.org/blog/2009/06/23/unodc-2008-coca-data-andean-region> Acesso em: 2009.

JUST THE FACTS. Disponível em: <http://justf.org/blog/2009/06/23/unodc-2008-coca-dataandean-region $>$ Acesso em: out. 2011.

KEEN, David. Sistemas de guerra: local y global. Revista Académica de Relaciones Internacionales, n. 6, abr. 2007. UAM-AEDRI, p. 3 
KOPP, Pierre. A economia da droga. Bauru: Edusc, 1998.

LAYTON, Julia (2011). Como funciona a lavagem de dinheiro. How Suff Works. Disponível em: $<$ http://empresasefinancas.hsw.uol.com.br/lavagem-de-dinheiro.htm>.

MARQUEZ-ESCOBAR, Pablo. "Economía de la inversión estranjera en Colombia”. Paper disponível em: <http://129.3.20.41/eps/it/papers/0404/0404003.pdf> Acesso em: out. 2011.

MINISTERIO DE DEFENSA NACIONAL. Bogotá, Cálculo del Gasto en Defensa y Seguridad — GDS, Notas de Investigación 01. Disponível em: <http://www.mindefensa.gov.co/irj/go/km/ docs/Mindefensa/Documentos/descargas2/anexos/9101_Nota_de_investigacion_O1_Calculo_ GDS.pdf> Acesso em: 2009.

NIZKOR- Derechos Human Rights el 06octo1. Los Jinetes de la Cocaína. Disponível em: <http:// www.derechos.org/nizkor/colombia/libros/jinetes/cap7.html> Acesso em: 2011.

PERRY, Guillero R. El financiamiento de los gastos en defensa: un debate importante. Economía y política - Fedesarrollo, jun. 2009.

PRADA, Diego Otero. Experiencias de investigación: las cifras del conflicto colombiano. Bogotá, 2008. p.18.

SANABRIA DUQUE, Álvaro. Ocho años de un gris plomizo. Le Monde Diplomatique Colombia, Bogotá, Edição 78, 2009. Disponível em: <http://eldiplo.info/mostrar_articulo.php?id=903\&numero= 78> Acesso em: 5 jan. 2010.

SILVA, Ademir A. "Notas sobre a política penitenciária brasileira". São Paulo, PUC/SP, ponto-e-vírgula, 7: p. 200-223. Disponível em: <http://www.pucsp.br/ponto-e-virgula/n7/artigos/pdf/ pv7-16-ademirsilva.pdf> Acesso em: 2011.

STOKES, Doug. Terrorismo, petróleo e capital: a contrainsurgência norte-americana na Colômbia. In: O império reloaded. São Paulo: Merlin Press Clacso, 2006. p. 266.

THOUMI, Franciso. Ilegal Drugs, Economy and Society in the Andes. Woodrow Wilson Center Press, 2003.

TOBAR, Yaneth G.; REYES, Héctor R.; VELASCO, Andrés S. "El gasto militar en Colombia: aspectos macroeconómicos y microeconómicos”. Santiago, Cepal, Revista de la Cepal, 69, p. 163-180, 1999.

TODOROV, T. O homem desenraizado. Rio de Janeiro: Record, 1999. 